\title{
Non-isothermal reaction mechanism and kinetic analysis for the synthesis of monoclinic lithium zirconate $\left(\mathrm{m}-\mathrm{Li}_{2} \mathrm{ZrO}_{3}\right)$ during solid-state reaction
}

\author{
Juan P. Yasnó ${ }^{1 *}$, Susana Conconi ${ }^{1,2}$, Arnaldo Visintin ${ }^{2,3}$ and Gustavo Suárez ${ }^{1,2}$
}

\begin{abstract}
Non-isothermal reaction mechanism and kinetic analysis for the synthesis of monoclinic lithium zirconate (m$\mathrm{Li}_{2} \mathrm{ZrO}_{3}$ ) were investigated by processing of TG-DTA, along with XRD, DLS, and HRTEM. For this purpose, the solidstate reaction of $\mathrm{Li}_{2} \mathrm{CO}_{3}$ with $\mathrm{ZrO}_{2}$ was carried out by TG-DTA at different heating rates $\left(10,20\right.$, and $\left.30^{\circ} \mathrm{C} / \mathrm{min}\right)$ from room temperature to $1100^{\circ} \mathrm{C}$. The thermal data was used to calculate the kinetic parameters by two types of isoconversional methods: Flynn-Wall-Ozawa (FWO) and Kissinger-Akahira-Sunose (KAS). The reaction mechanism was determined by the model-fitting method, applying the Coats-Redfern (CR) approximation to the different solidstate reaction models. The results confirmed the formation of pure $\mathrm{m}-\mathrm{Li}_{2} \mathrm{ZrO}_{3}$, consists of semispherical particles of about $490 \mathrm{~nm}$, using a very short reaction time. The average activation energy obtained by FWO and KAS methods were 274.73 and $272.50 \mathrm{~kJ} / \mathrm{mol}$, respectively. It was found that the formation of $\mathrm{m}-\mathrm{Li}_{2} \mathrm{ZrO}_{3}$ from $\mathrm{Li}_{2} \mathrm{CO}_{3}$ with $\mathrm{ZrO}_{2}$ is governed by the three-dimensional diffusion mechanism. Based on these results, a microscopic reaction model of the formation of $\mathrm{m}-\mathrm{Li}_{2} \mathrm{ZrO}_{3}$ was proposed.
\end{abstract}

Keywords: $\mathrm{M} \mathrm{Li}_{2} \mathrm{ZrO}_{3}$, Solid-state reaction kinetics, Non-isothermal, TG-DTA, XRD

\section{Introduction}

Monoclinic lithium zirconate $\left(\mathrm{m}-\mathrm{Li}_{2} \mathrm{ZrO}_{3}\right)$ is a ceramic material that has potential applications in different fields including solid-state lithium-ion batteries (Dong et al. 2015; Sherstobitova et al. 2016; Zhan et al. 2018), solid sorbent for $\mathrm{CO}_{2}$ capture (Ida and Lin 2003; Kordatos et al. 2017; Chattaraj 2017), and nuclear reactors (Taddia et al. 2005; Oyaidzu et al. 2006; Chitnis et al. 2018). While $\mathrm{m}-\mathrm{Li}_{2} \mathrm{ZrO}_{3}$ is conventionally prepared via solidstate reaction of $\mathrm{Li}_{2} \mathrm{CO}_{3}$ with $\mathrm{ZrO}_{2}$ (see Eq.(1)) (Wyers and Cordfunke 1989; Pfeiffer and Knowles 2004; Sree Rama Murthy et al. 2017), its formation kinetics has not been reported in the scientific literature. In the

\footnotetext{
*Correspondence: jpyasno@cetmic.unlp.edu.ar; jpyasno@hotmail.com 'CETMIC Technological Center of Mineral Resources and Ceramics (UNLP-CIC-CONICET), Cno. Centenario y 506, M.B. Gonnet, 1897 Buenos Aires, Argentina

Full list of author information is available at the end of the article
}

bibliographic review on reaction kinetics, a study was found on the decomposition of $\mathrm{m}-\mathrm{Li}_{2} \mathrm{ZrO}_{3}$ into $\mathrm{ZrO}_{2}$ (Pfeiffer and Knowles 2004). It is worth highlighting the fact that the knowledge of the reaction kinetics and mechanism are very important in order to optimize the solid-state process for large-scale production and advanced applications. Moreover, reasonable mechanistic conclusions can be drawn from the kinetic data ( $\mathrm{Lu}$ and Wu 2008; Mandal 2014).

$$
\mathrm{Li}_{2} \mathrm{CO}_{3}+\mathrm{ZrO}_{2} \stackrel{\Delta}{\rightarrow} m-\mathrm{Li}_{2} \mathrm{ZrO}_{3}+\mathrm{CO}_{2} \uparrow
$$

Some of the analytical methods used to study the reaction kinetics in the solid-state are thermogravimetric analysis (TGA), differential-thermal analysis (DTA), Xray diffraction $(\mathrm{XRD})$, differential-scanning calorimetry (DSC), and nuclear magnetic resonance (NMR) (Mandal 2014; Vyazovkin et al. 2011; Khawam and Flanagan 
2006; Ghuge and Mandal 2017). For any one of these methods, the measured parameter must be able to be transformed into the change in extent of reaction $(\alpha)$, which can be used in the kinetics analysis by either isoconversional (model-free) or model-fitting (Khawam and Flanagan 2006). The combination of both methods can result in a more complete kinetics analysis ( $\mathrm{Lv}$ et al. 2018; Khawam and Flanagan 2005; Pratap et al. 2007). The most common analytical method used in kinetic analysis is TGA due its simplicity and good repeatability (Khawam and Flanagan 2006; Ghuge and Mandal 2017; Ebrahimi-Kahrizsangi and Abbasi 2008; Jiang and Wei 2018; Liu et al. 2020; Marinović-Cincović et al. 2013). It has been involved in the study, only by model-fitting method, of the reaction kinetics for the synthesis of other Li-based ceramics such as $\mathrm{Li}_{2} \mathrm{TiO}_{3}$ (Mandal 2014), $\mathrm{LiDyO}_{2}$ (Ghuge and Mandal 2017), and $\mathrm{LiNiO}_{2}$ (Lu and Wei-Cheng 2000).

In this context, the aim of this work is to study the reaction mechanism and kinetics analysis of $\mathrm{m}-\mathrm{Li}_{2} \mathrm{ZrO}_{3}$ in a solid-state reaction of $\mathrm{Li}_{2} \mathrm{CO}_{3}$ and $\mathrm{ZrO}_{2}$ by TGA, along with DTA, XRD, dynamic light scattering (DLS), and high-resolution transmission electron microscopy HRTE $\mathrm{M}$, by both isoconversional (model-free) and modelfitting methods, considering the relationship between $\alpha$ and reaction temperature during heating. For this purpose, the kinetic parameters (activation energy: $\mathrm{Ea}$, and pre-exponential factor: A) were calculated by two types of isoconversional methods: Flynn-Wall-Ozawa (FWO) and Kissinger-Akahira-Sunose (KAS) (Vyazovkin et al. 2011; Khawam and Flanagan 2006; Jiang and Wei 2018). Moreover, the reaction kinetics was determined by the model-fitting method, applying the Coats-Redfern (CR) approximation to the different solid-state reaction models (nucleation, diffusion, geometrical contraction, and reaction order model) (Khawam and Flanagan 2006; Ghuge and Mandal 2017; Lv et al. 2018; Milićević et al. 2017). To the best of our knowledge, this is the first report on the non-isothermal reaction mechanism and kinetic analysis for the synthesis of $\mathrm{m}-\mathrm{Li}_{2} \mathrm{ZrO}_{3}$.

\section{Experimental procedure}

\section{Materials preparation and characterization}

$\mathrm{m}-\mathrm{Li}_{2} \mathrm{ZrO}_{3}$ was prepared by using $\mathrm{Li}_{2} \mathrm{CO}_{3}$ (Cicarelli, 99\%) and $\mathrm{ZrO}_{2}$ (Tosoh, 99.9\%) as the starting materials. Both the reactants were ball-milled with ethanol $\left(\mathrm{C}_{2} \mathrm{H}_{6} \mathrm{O}\right)$ for $20 \mathrm{~h}$ at $60 \mathrm{rpm}$ using $\mathrm{ZrO}_{2}$ balls $(2 \mathrm{~cm}$ in diameter). The obtained mixture was dried in an oven at $110{ }^{\circ} \mathrm{C}$, and homogenized by grinding and sieving (\#100) processes. Finally, the reaction was conducted by TGDTA (Rigaku, Evo2) from room temperature to $1100{ }^{\circ} \mathrm{C}$, at three different heating rates $\left(10,20\right.$, and $\left.30{ }^{\circ} \mathrm{C} / \mathrm{min}\right)$ under air atmosphere. The measurement conditions were as follows: sample weight $80-82 \mathrm{mg}$, gas flow 50 $\mathrm{ml} / \mathrm{min}$, and alumina pan. For the analysis of phase formation, the reaction of the precursor was also conducted by heating in an electrical furnace at different temperatures under similar conditions to TG-DTA experiments. After cooling at room temperature, the samples were characterized by XRD (Philips, PW3710) with $\mathrm{Cu}-\mathrm{K} \alpha$ radiation $(\lambda=0.154 \mathrm{~nm})$, operating at $35 \mathrm{kV}$ and $40 \mathrm{~mA}$, in the $2 \theta$ range of $15-80^{\circ}$ with a step width of $0.04^{\circ}$. The average particle size (D) of the as-prepared samples was obtained by DLS (Brookhaven, 90Plus) with a solid-state laser $(\lambda=658 \mathrm{~nm})$ and scattering angle of $90^{\circ}$. For this purpose, sample suspensions were prepared using $10^{-3}$ $\mathrm{M} \mathrm{KCl}$ solutions and sonicated for $30 \mathrm{~min}$. The morphology and microstructure of pure $\mathrm{m}-\mathrm{Li}_{2} \mathrm{ZrO}_{3}$ were examined by HRTEM (FEI Talos, F200X).

\section{Kinetic analysis}

Based on TGA, the change in extent of reaction or conversion rate $(\alpha)$, and the non-isothermal rate of the solid-state reaction $(d \alpha / d T)$ can be described by Eqs. (2) and (3), respectively (Vyazovkin et al. 2011; Li et al. 2020; Trawiński et al. 2020; Vyazovkin et al. 2014).

$$
\alpha=\frac{m_{i}-m_{t}}{m_{i}-m_{\infty}}
$$

Where, $m_{i}, m_{t}$, and $m_{\infty}$ are initial weight of the $\mathrm{Li}_{2} \mathrm{CO}_{3}-\mathrm{ZrO}_{2}$ mixture, the reactant weight at time $t$, and the final weight at the end of reaction, respectively. This data was obtained from TGA results.

$$
\frac{d \alpha}{d T}=\frac{A}{\beta} e^{-\frac{E a}{R \cdot T}} f_{(\alpha)}
$$

Where, A, $\beta, E_{\mathrm{a}}, \mathrm{R}$, and $f(\alpha)$ are the pre-exponential factor, the heating rate, the activation energy, the universal gas constant, and the differential form of the kinetic model, respectively. Equation (3) can be expressed in integral form by Eq. (4), considering the integral reaction model $g(\alpha)$, which is defined by Eq. (5) (Vyazovkin et al. 2011; Khawam and Flanagan 2006; EbrahimiKahrizsangi and Abbasi 2008).

$$
\begin{aligned}
& g_{(\alpha)}=\frac{A}{\beta} \int_{0}^{T} e^{-\frac{E_{a}}{R \cdot T}} d T \\
& g_{(\alpha)}=\int_{0}^{T} \frac{d \alpha}{f_{(\alpha)}}
\end{aligned}
$$

Kinetic analysis can be used to describe a thermally active process by determining three factors: activation energy, pre-exponential factor, and reaction model (Jiang and Wei 2018). Two methods, that is, the isoconversional (model-free) and model-fitting can be used to study the kinetics of a solid-state reaction. Typically, isoconversional methods have been used to determine the 
activation energy and pre-exponential factor without assuming any particular form of the reaction model, while model fitting method is used to determine the reaction model (Vyazovkin et al. 2011; Khawam and Flanagan 2006; Lee et al. 2016). Therefore, the combination of both methods was used in this work in order to obtain a complete description of the solid-state reaction of $\mathrm{Li}_{2} \mathrm{CO}_{3}$ and $\mathrm{ZrO}_{2}$ to form m- $\mathrm{Li}_{2} \mathrm{ZrO}_{3}$.

\section{Isoconversional (model-free) methods}

All the isoconversional methods assume that the activation energy corresponding to the same conversion rate remains the same under different conditions of temperature rise. Here, the kinetic parameters are obtained without assuming the reaction model. Because the integral in Eq. (4) does not have an analytical solution, a number of approximate solutions were developed. Many of these approximations give rise to linear equations, such as the Flynn-Wall-Ozawa (FWO) and Kissinger-Akahira-Sunose (KAS) methods, which are described by Eq. (6) and (7), respectively (Vyazovkin et al. 2011; Jiang and Wei 2018).

$$
\begin{aligned}
& \ln \beta=-1.052 \frac{E_{a}}{R \cdot T}+\ln \left(\frac{A \cdot E_{a}}{R \cdot g_{(\alpha)}}\right)-5.331 \\
& \ln \left(\frac{\beta}{T^{2}}\right)=-\frac{E_{a}}{R \cdot T}+\ln \left(\frac{A \cdot R}{E_{a} \cdot g_{(\alpha)}}\right)
\end{aligned}
$$

These equations are relatively simple to solve by applying linear regression analysis (Vyazovkin et al. 2011), making it possible to calculate the kinetic parameters involved in every equation. This procedure was as follows:

- $\alpha$ versus T was obtained from TGA results at three different heating rates $\left(10,20\right.$, and $\left.30^{\circ} \mathrm{C} / \mathrm{min}\right)$. The values of $\alpha$ were chosen between 0.1 and 0.9 (Vyazovkin et al. 2020) with a step of 0.05 .

- By using the slope-intercept form of a linear equation $(y=m x+b$, where $m$ is the slope and $b$ is the $y$ intercept), Eq. (6) and (7) can be expressed by Eq. (8) and (9), respectively.

$$
\begin{aligned}
& \ln \beta=y_{\mathrm{FWO}}=m_{\mathrm{FWO}}\left(\frac{1}{T}\right)+b_{\mathrm{FWO}} \\
& \ln \left(\frac{\beta}{T^{2}}\right)=y_{\mathrm{KAS}}=m_{\mathrm{KAS}}\left(\frac{1}{T}\right)+b_{\mathrm{KAS}}
\end{aligned}
$$

Therefore, the values of $\ln \beta$ (FWO method) and $\ln (\beta /$ $T^{2}$ ) (KAS method) versus $(1 / T)$ were plotted at the same value of $\alpha$ (from $\alpha$ versus $T$ relationships obtained at different heating rates), respectively.

- The activation energy and pre-exponential factor were determined from the slopes and intercepts, in each case (Lv et al. 2018; Jiang and Wei 2018), which, according to Eqs. (6)-(9), can be described as follows:

$$
\begin{aligned}
& E a_{\mathrm{FWO}}=-\frac{R}{1.052} m_{\mathrm{FWO}} \\
& E a_{\mathrm{KAS}}=-R \cdot m_{\mathrm{KAS}} \\
& A_{\mathrm{FWO}}=-R \cdot e^{\left(b_{\mathrm{FWO}}+5.331\right)} \cdot g_{(\alpha)} \frac{1}{E a_{\mathrm{FWO}}} \\
& A_{\mathrm{KAS}}=\frac{e^{b_{\mathrm{KAS}}} \cdot g_{(\alpha)}}{R} E a_{\mathrm{KAS}}
\end{aligned}
$$

\section{Model-fitting method}

Different reaction models used in the solid-state kinetics are listed in Table 1.

All model-fitting methods assume that a particular reaction model represents the conversion dependence of the reaction rate (Vyazovkin et al. 2011). The most commonly used model-fitting methods is Coats-Redfern (CR) approximation, described by Eq. (14) (Ghuge and Mandal 2017; Lv et al. 2018; Pratap et al. 2007). This approximation was applied on the different reactions models listed in Table 1, and the best suited model for fitting was defined as the solid-state reaction mechanism.

$$
\ln \left(\frac{g_{(\alpha)}}{T^{2}}\right)=\ln \left(\frac{\mathrm{AR}}{\beta E_{a}}\left(1-\frac{2 \mathrm{R} \overline{\mathrm{T}}}{E_{a}}\right)\right)-\frac{E_{a}}{\mathrm{RT}}
$$

\section{Results and discussion}

XRD patterns of $\mathrm{Li}_{2} \mathrm{CO}_{3}-\mathrm{ZrO}_{2}$ mixtures heated at temperatures from $600{ }^{\circ} \mathrm{C}$ to $1100{ }^{\circ} \mathrm{C}$ are shown in Fig. 1 . $\mathrm{XRD}$ pattern of the precursor (at room temperature) was included for comparison. As can be seen in Fig. 1, the samples obtained after heat treatment at $600{ }^{\circ} \mathrm{C}$ and $650{ }^{\circ} \mathrm{C}$ do not exhibit a significant difference when compared with the precursor, suggesting that $\mathrm{Li}_{2} \mathrm{CO}_{3}$ (JCPDS 80-1307) did not react with $\mathrm{ZrO}_{2}$ (JCPDS 83-944) at temperatures below $650{ }^{\circ} \mathrm{C}$. When the temperature was increased to $700{ }^{\circ} \mathrm{C}$, tetragonal $\mathrm{Li}_{2} \mathrm{ZrO}_{3}$ (mainly t- $\mathrm{Li}_{2} \mathrm{ZrO}_{3}$ (JCPDS 20-647), along with $\mathrm{t}^{\prime}-\mathrm{Li}_{2} \mathrm{ZrO}_{3}$ traces (JCPDS 41$324)$ ), and hexa-lithium zirconate $\left(\mathrm{Li}_{6} \mathrm{Zr}_{2} \mathrm{O}_{7}\right.$, JCPDS 36122) were formed, while $\mathrm{ZrO}_{2}$ and $\mathrm{Li}_{2} \mathrm{CO}_{3}$ peaks decreased significantly. This implies that a large amount 
Table 1 Different reaction models used in the solid-state kinetics (Vyazovkin et al. 2011; Khawam and Flanagan 2006; Milićević et al. 2017; Vyazovkin et al. 2014)

\begin{tabular}{|c|c|c|c|}
\hline$\#$ & Reaction model & $f(a)$ & $g(a)$ \\
\hline \multicolumn{4}{|c|}{ Nucleation models } \\
\hline 1 & Power law (P2) & $2 a^{1 / 2}$ & $a^{1 / 2}$ \\
\hline 2 & Power law (P3) & $3 a^{2 / 3}$ & $a^{1 / 3}$ \\
\hline 3 & Power law (P4) & $4 a^{3 / 4}$ & $a^{1 / 4}$ \\
\hline 4 & Avrami-Erofeyev (A2) & $2(1-a)[-\ln (1-a)]^{1 / 2}$ & {$[-\ln (1-a)]^{1 / 2}$} \\
\hline 5 & Avrami-Erofeyev (A3) & $3(1-a)[-\ln (1-a)]^{2 / 3}$ & {$[-\ln (1-a)]^{1 / 3}$} \\
\hline 6 & Avrami-Erofeyev (A4) & $4(1-a)[-\ln (1-a)]^{3 / 4}$ & {$[-\ln (1-a)]^{1 / 4}$} \\
\hline 7 & Modified Prout-Tompkins (B1) & $a(1-a)$ & $\ln [a /(1-a)]$ \\
\hline \multicolumn{4}{|c|}{ Geometrical contraction models } \\
\hline 8 & Contracting area (R2) & $2(1-a)^{1 / 2}$ & $1-(1-a)^{1 / 2}$ \\
\hline 9 & Contracting volume (R3) & $3(1-a)^{2 / 3}$ & $1-(1-a)^{1 / 3}$ \\
\hline \multicolumn{4}{|c|}{ Diffusion models } \\
\hline 10 & One-dimensional diffusion (D1) & $1 /(2 a)$ & $a^{2}$ \\
\hline 11 & Two-dimensional diffusion (D2) & $-[1 / \ln (1-a)]$ & $((1-a) \ln (1-a))+a$ \\
\hline 12 & Three-dimensional diffusion (D3) & {$\left[3(1-a)^{2 / 3}\right] /\left[2\left(1-(1-a)^{1 / 3}\right)\right]$} & $\left(1-(1-a)^{1 / 3}\right)^{2}$ \\
\hline 13 & Ginstling-Brounshtein (D4) & $3 /\left[2\left(1-(1-a)^{-1 / 3}-1\right)\right]$ & $1-(2 / 3) a-(1-a)^{2 / 3}$ \\
\hline \multicolumn{4}{|c|}{ Reaction-order models } \\
\hline 14 & Zero-order (F0/R1) & 1 & $a$ \\
\hline 15 & First-order (F1) & $(1-a)$ & $-\ln (1-a)$ \\
\hline 16 & Second-order (F2) & $(1-a)^{2}$ & {$[1 /(1-a)]-1$} \\
\hline 17 & Third-order (F3) & $(1-a)^{3}$ & $(1 / 2)\left[(1-a)^{-2}-1\right]$ \\
\hline
\end{tabular}

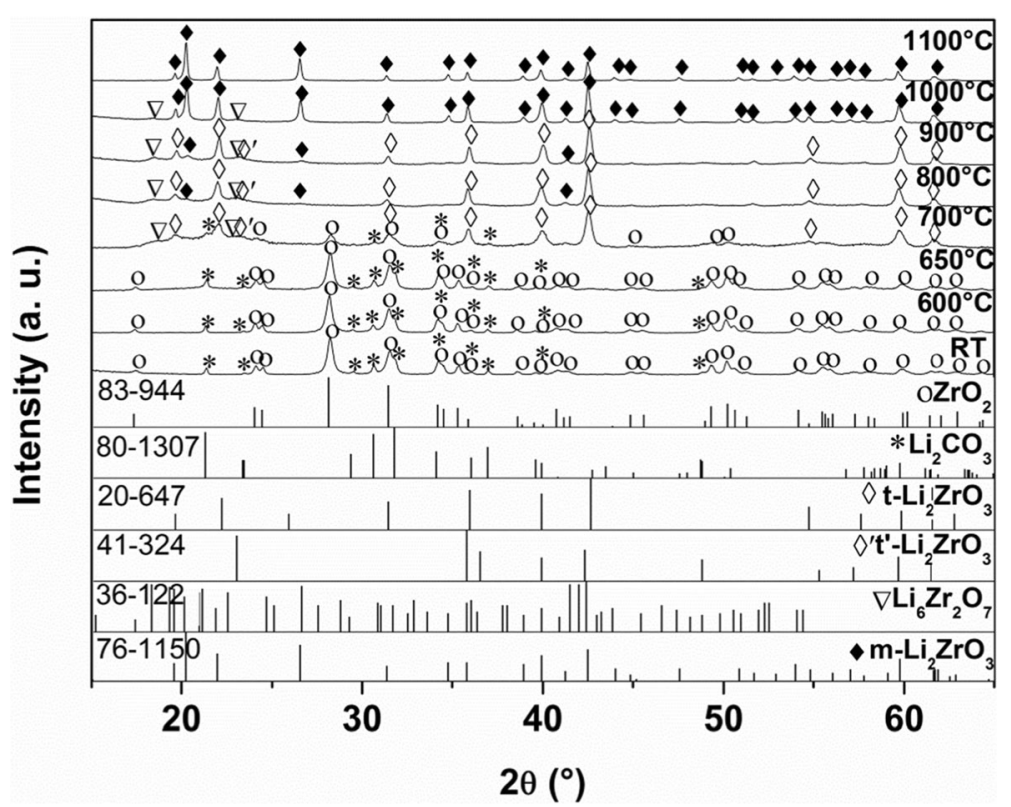

Fig. 1 XRD patterns of $\mathrm{Li}_{2} \mathrm{CO}_{3}-\mathrm{ZrO}_{2}$ mixtures at room temperature (RT) and heated at different temperatures 
of $\mathrm{Li}_{2} \mathrm{CO}_{3}$ can be consumed by both the direct reaction with $\mathrm{ZrO}_{2}$ in order to form $\mathrm{Li}-\mathrm{Zr}-\mathrm{O}$ compounds, and its decomposition. The reaction between $\mathrm{Li}_{2} \mathrm{CO}_{3}$ and $\mathrm{ZrO}_{2}$ can result in the formation of tetragonal $\mathrm{Li}_{2} \mathrm{ZrO}_{3}$ (see Eq. (15)) since this symmetry can exist as a metastable polymorph at temperature below $900{ }^{\circ} \mathrm{C}$ (Wang et al. 2013). The formation of $\mathrm{Li}_{6} \mathrm{Zr}_{2} \mathrm{O}_{7}$ can be attributed to small heterogeneities in the sample that result in a local variation of the stoichiometry, favoring the reaction described by Eq. (16) (Pfeiffer and Knowles 2004; Wang et al. 2014). In order to confirm the decomposition of $\mathrm{Li}_{2} \mathrm{CO}_{3}$ in this temperature range, TG-DTA for pure $\mathrm{Li}_{2} \mathrm{CO}_{3}$ was performed (see Fig. 2). According to the results shown in Fig. 2, it was indeed found that $\mathrm{Li}_{2} \mathrm{CO}_{3}$ melts and decomposes at temperatures above $700{ }^{\circ} \mathrm{C}$ (see Eq. (17)), in accordance with those results found in literature (Ida and Lin 2003; Mandal 2014; Lu and WeiCheng 2000). When the temperature reached $800{ }^{\circ} \mathrm{C}$, a small amount of $\mathrm{m}-\mathrm{Li}_{2} \mathrm{ZrO}_{3}$ (JCPDS 76-1150) was formed, while $\mathrm{ZrO}_{2}$ and $\mathrm{Li}_{2} \mathrm{CO}_{3}$ were not detected. Tetragonal $\mathrm{Li}_{2} \mathrm{ZrO}_{3}$ and $\mathrm{Li}_{6} \mathrm{Zr}_{2} \mathrm{O}_{7}$ phases remain in the sample. This implies that at this temperature the remaining $\mathrm{ZrO}_{2}$ and $\mathrm{Li}_{2} \mathrm{CO}_{3}$ were consumed to form $\mathrm{Li}_{2} \mathrm{ZrO}_{3}$ (tetragonal and monoclinic) and $\mathrm{Li}_{6} \mathrm{Zr}_{2} \mathrm{O}_{7}$. At $900{ }^{\circ} \mathrm{C}$, the XRD pattern was not significantly modify, the only difference is a small increase in the amount of $\mathrm{m}-\mathrm{Li}_{2} \mathrm{ZrO}_{3}$, which can be attributed to a partial phase transition from tetragonal to monoclinic $\mathrm{Li}_{2} \mathrm{ZrO}_{3}$ (see Eq. (18)). This transition was favored at higher temperatures, being completed at $1000{ }^{\circ} \mathrm{C}$, as shown in Fig. 1, where only the monoclinic polymorph of $\mathrm{Li}_{2} \mathrm{ZrO}_{3}$ is observed. In this XRD pattern, $\mathrm{m}-\mathrm{Li}_{2} \mathrm{ZrO}_{3}$ became the main crystalline phase, along with $\mathrm{Li}_{6} \mathrm{Zr}_{2} \mathrm{O}_{7}$ traces. Finally, when the temperature reached $1100{ }^{\circ} \mathrm{C}$, pure $\mathrm{m}-\mathrm{Li}_{2} \mathrm{ZrO}_{3}$ was obtained, implying the decomposition of $\mathrm{Li}_{6} \mathrm{Zr}_{2} \mathrm{O}_{7}$ traces according to Eq. (19) (Pfeiffer and Knowles 2004).

$$
\begin{aligned}
& \mathrm{Li}_{2} \mathrm{CO}_{3}+\mathrm{ZrO}_{2} \stackrel{\Delta}{\rightarrow}\left(\text { t or t } t^{\prime}\right)-\mathrm{Li}_{2} \mathrm{ZrO}_{3}+\mathrm{CO}_{2} \uparrow \\
& 3 \mathrm{Li}_{2} \mathrm{CO}_{3}+2 \mathrm{ZrO}_{2} \stackrel{\Delta}{\rightarrow} \mathrm{Li}_{6} \mathrm{Zr}_{2} \mathrm{O}_{7}+3 \mathrm{CO}_{2} \uparrow \\
& \mathrm{Li}_{2} \mathrm{CO}_{3} \stackrel{\Delta}{\rightarrow} \mathrm{Li}_{2} \mathrm{O}+\mathrm{CO}_{2} \uparrow \\
& \left(\text { tor } t^{\prime}\right)-\mathrm{Li}_{2} \mathrm{ZrO}_{3} \stackrel{\Delta}{\rightarrow} m-\mathrm{Li}_{2} \mathrm{ZrO}_{3} \\
& \mathrm{Li}_{6} \mathrm{Zr}_{2} \mathrm{O}_{7} \stackrel{\Delta}{\rightarrow} 2 m-\mathrm{Li}_{2} \mathrm{ZrO}_{3}+\mathrm{Li}_{2} \mathrm{O} \uparrow
\end{aligned}
$$

TGA and DTA curves of $\mathrm{Li}_{2} \mathrm{CO}_{3}-\mathrm{ZrO}_{2}$ mixtures at different heating rates $\left(10,20\right.$, and $\left.30{ }^{\circ} \mathrm{C} / \mathrm{min}\right)$ are shown in Fig. 3a, b, respectively. Figure 3a shows that in TGA curve obtained at $10{ }^{\circ} \mathrm{C} / \mathrm{min}$, the weight loss was greatly affected by increasing temperature approximately between $600{ }^{\circ} \mathrm{C}$ and $750{ }^{\circ} \mathrm{C}$. This weight loss can be attributed to $\mathrm{CO}_{2}$ losses though both the direct reaction of $\mathrm{Li}_{2} \mathrm{CO}_{3}$ with $\mathrm{ZrO}_{2}$ to form $\mathrm{Li}-\mathrm{Zr}-\mathrm{O}$ compounds, and the decomposition of $\mathrm{Li}_{2} \mathrm{CO}_{3}$, as explained above (see Eq. $15-17$ ). The overall weight loss was about $23 \%$, which is consistent with the values found in the literature for this type of reaction (Pfeiffer and Knowles 2004; Woo et al. 2006). When the heating rate was increased, the trend of the TGA curves was similar, but with a slight shift towards higher temperatures, as can be observed in Fig. 3a. This can be associated with heat transfer limitations during the analysis, since, even if a slow heating rate is favorable to approach thermal equilibrium due to a larger instantaneous thermal energy is provided to the sample, a fast heating rate can generate a thermal lag between the heating source and the sample, therefore, the

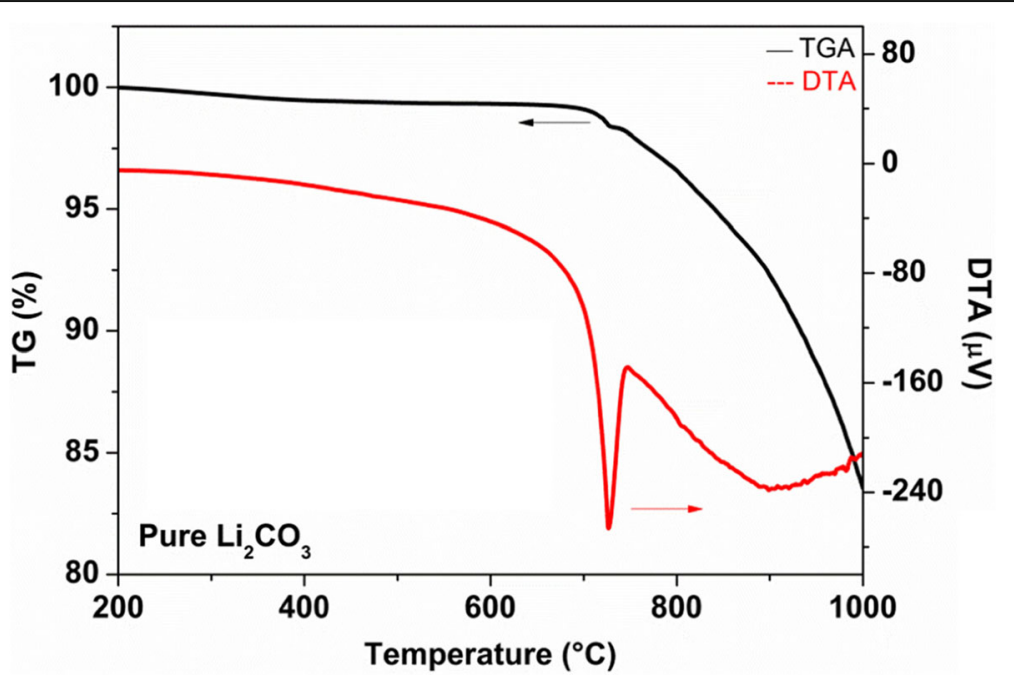

Fig. 2 TG-DTA curves of pure $\mathrm{Li}_{2} \mathrm{CO}_{3}$ at $10{ }^{\circ} \mathrm{C} / \mathrm{min}$ 


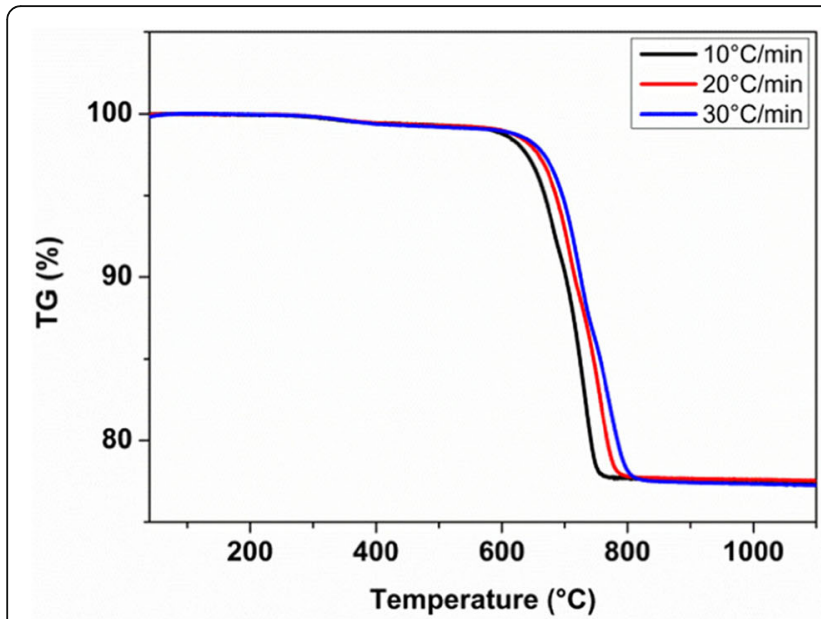

(a)

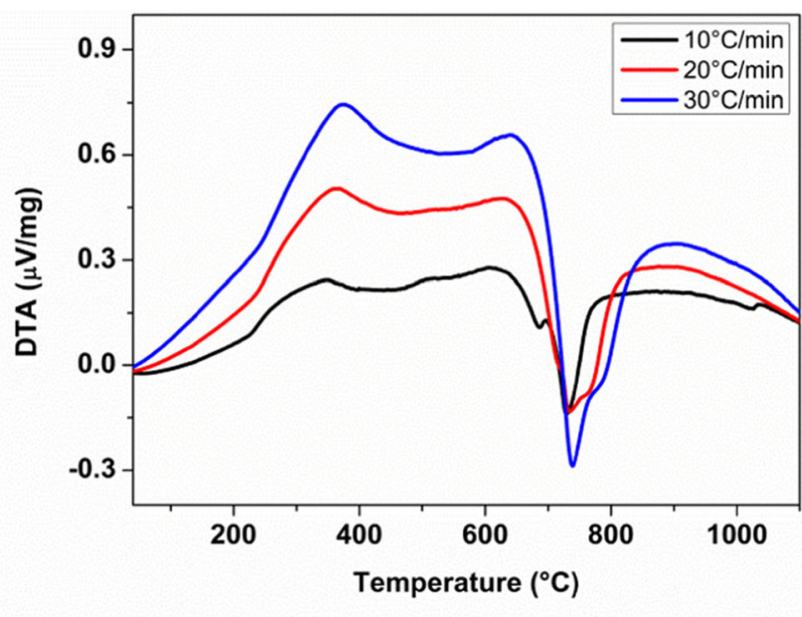

(b)

Fig. 3 a TGA and $\mathbf{b}$ DTA curves of $\mathrm{Li}_{2} \mathrm{CO}_{3}-\mathrm{ZrO}_{2}$ mixture at different heating rates

temperature gradient across the sample is more pronounced (Leng 2013; Kongkaew et al. 2015). That is why slightly higher temperatures were required to complete the reactions of decomposition of $\mathrm{Li}_{2} \mathrm{CO}_{3}$ and formation of $\mathrm{Li}-\mathrm{Zr}-\mathrm{O}$ compounds at faster heating rates. On the other hand, Fig. 3b shows that the DTA curve obtained at $10{ }^{\circ} \mathrm{C} / \mathrm{min}$ presents a dual endothermic effect between $650{ }^{\circ} \mathrm{C}$ and $800{ }^{\circ} \mathrm{C}$, which can be attributed to reactive $\mathrm{Li}_{2} \mathrm{CO}_{3}$ reacting with $\mathrm{ZrO}_{2}$, and the melting and decomposition of $\mathrm{Li}_{2} \mathrm{CO}_{3}$, in accordance with the XRD and TG-DTA results shown above. When the heating rate was increased, this region became broader. This can be due to that when the thermal equilibrium was reached at slow heating rate, the sample stayed long time at this temperature, favoring the reactions in all of the material and the formation of endothermic peaks in the DTA, while at faster heating rates a temperature gradient was generated; therefore, this region was extended to higher temperatures until the reactions were completed.

Figure 4 shows the variation of $\alpha$ as a function of temperature at different heating rates for TGA experiments. As can be seen, the trend of the variation of $\alpha$ as a function of temperature was similar for the different heating rates. In general, it can be observed that $\alpha$ increased significantly at temperatures approximately between $600{ }^{\circ} \mathrm{C}$ and $750-800{ }^{\circ} \mathrm{C}$, implying the formation of

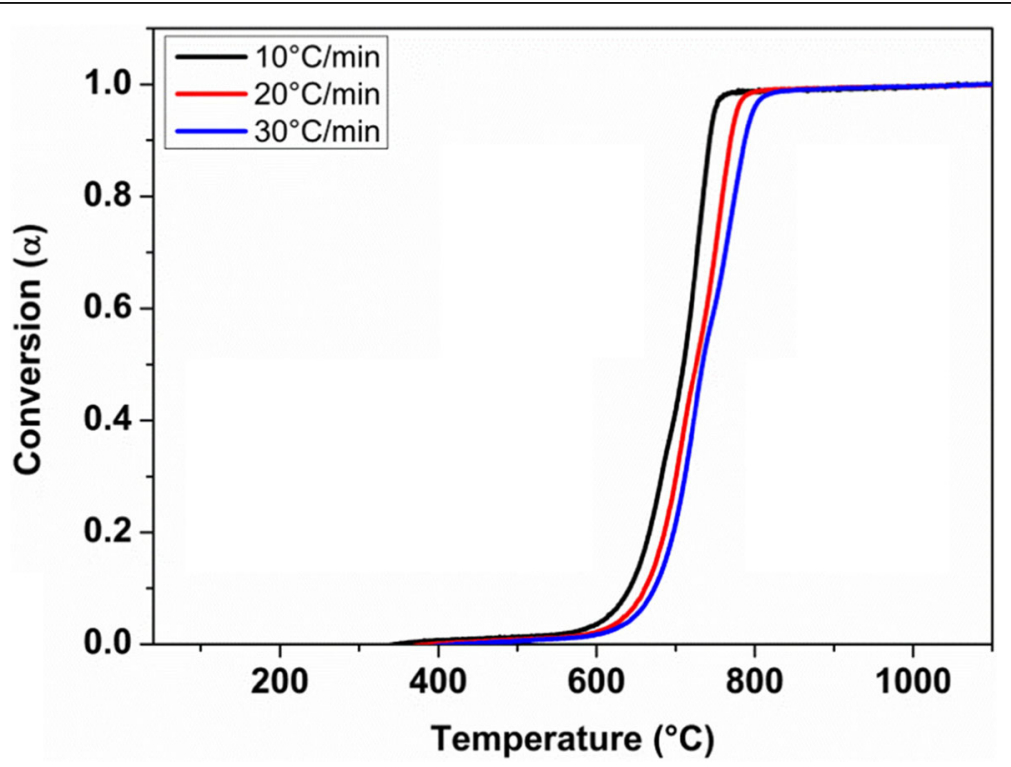

Fig. 4 Variation of a for TGA experiments 
$\mathrm{Li}-\mathrm{Zr}$-O compounds. The slightly shift to the right in the curves obtained at higher heating rates is associated to that higher temperatures were required to complete the reactions, as explained for TG-DTA curves in Fig. 2. Then, the conversion degree continued to increase slowly with increasing temperature till the end of the reaction at about $1100{ }^{\circ} \mathrm{C}$.

In order to determine the kinetic parameters through the isoconversional methods, the results obtained from Fig. 4 were used. The kinetic data of the reaction for the formation of $\mathrm{m}-\mathrm{Li}_{2} \mathrm{ZrO}_{3}$ were calculated by FWO and KAS methods from " $\ln \beta$ versus $(1 / \mathrm{T})$ ", and " $\ln \left(\frac{\beta}{T^{2}}\right)$ versus $(1 / \mathrm{T})$ " plots, which are shown in Figs. 5 and 6, respectively. In each case, the slopes and intercepts of fitted lines were used to calculate the apparent activation energy and pre-exponential factor, respectively, for a given value of $\alpha$.

Figure 7 shows the activation energy (Ea) as a function of $\alpha$. As it can be noted, the values of activation energy estimated by FWO method are similar with those obtained by KAS method, demonstrating a good agreement in the calculation of the kinetic data. According to these results, the overall reaction process can be divided into two stages, where the activation energy increased initially $(0<\alpha \leq 0.5)$, and then decreased gradually $(0.5<\alpha$ $<1)$. The values of the average activation energy were $293.25 \mathrm{~kJ} / \mathrm{mol}$ (FWO) and $292.42 \mathrm{~kJ} / \mathrm{mol}$ (KAS) for the first stage; and $256.21 \mathrm{~kJ} / \mathrm{mol}$ (FWO) and $252.58 \mathrm{~kJ} / \mathrm{mol}$ (KAS) for the second stage. The first stage can be due to that $\mathrm{Li}_{2} \mathrm{CO}_{3}$ reacted with $\mathrm{ZrO}_{2}$ to form tetragonal $\mathrm{Li}_{2} \mathrm{ZrO}_{3}$ and $\mathrm{Li}_{6} \mathrm{Zr}_{2} \mathrm{O}_{7}$ on the surface of $\mathrm{ZrO}_{2}$ particles.
With increasing temperature reaction, $\mathrm{Li}^{+}$diffused though the shell to the core of $\mathrm{ZrO}_{2}$ to thicken the product layer; therefore, the activation energy was increased. The final stage can be associated with the formation of $\mathrm{m}-\mathrm{Li}_{2} \mathrm{ZrO}_{3}$ by transformation of tetragonal $\mathrm{Li}_{2} \mathrm{ZrO}_{3}$, and decomposition of $\mathrm{Li}_{6} \mathrm{Zr}_{2} \mathrm{O}_{7}$ at higher temperatures, which result in a decrease in the activation energy. Thus, the average activation energy of the overall reaction process estimated by FWO and KAS methods were $274.73 \mathrm{~kJ} / \mathrm{mol}$ and $272.50 \mathrm{~kJ} / \mathrm{mol}$, respectively. In the case of the pre-exponential factor, the average values estimated by FWO and KAS methods were $2.63 \times 10^{20} / \mathrm{min}$ and $3.16 \times 10^{14} / \mathrm{min}$, respectively, indicating a highly reactive system $\left(\mathrm{A} \geq 10^{10} / \mathrm{min}\right)$ (Dhyani et al. 2017).

In order to determine the most probable reaction model, the Coats-Redfern (CR) approximation described by Eq. (14) was used. For this purpose, this approximation was applied on the different reactions models listed in Table 1 using the TGA data shown in Fig. 2a. The CR data $\left(\ln \left(g_{(\alpha)} / T^{2}\right)\right.$ versus $\left.1 / \mathrm{T}\right)$ for the reaction models of the solid-state reaction heated at different heating rates was fitted, and the values of the obtained $R^{2}$ are presented in Table 2.

A practical way to determine the best suitable solidstate reaction model was to look the model corresponding to maximum $R^{2}$ (Ghuge and Mandal 2017; Khawam and Flanagan 2005), according to the results obtained in Table 2. By applying this criterion for the analyzed data several equivalent models based on goodness of fit can be chosen; however, the three-dimensional diffusion model (D3, see Fig. 8) is found to more suitable for the

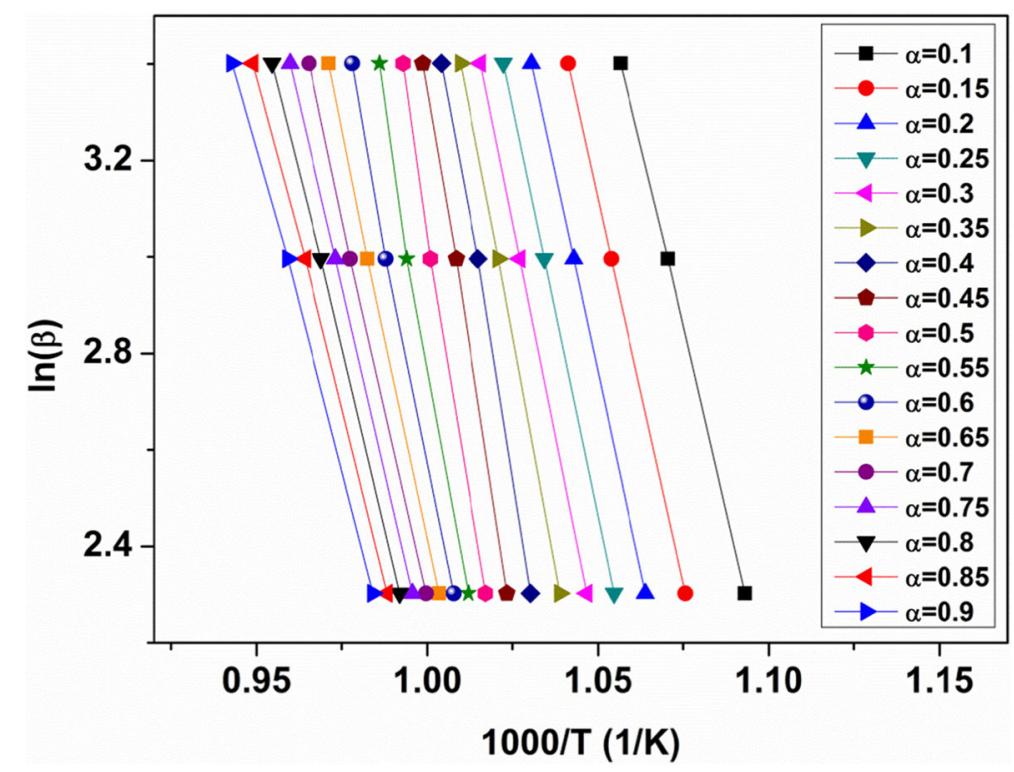

Fig. 5 FWO plot of the solid-state reaction for different values of a 


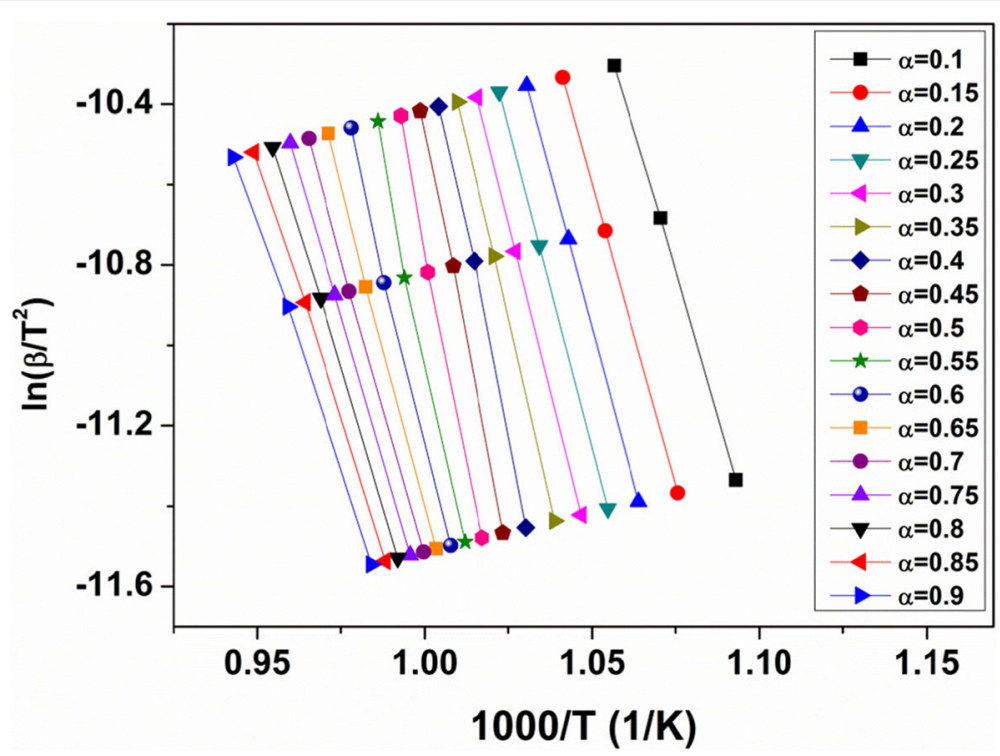

Fig. 6 KAS plot of the solid-state reaction for different values of a

description of the solid-state reaction not only because $R^{2}$ was a maximum for this model at each heating rate, but also because Ea for D3 obtained by CR method is consistent with the range of values obtained by FWO and KAS methods and near to their average values $(\sim 273$ $\mathrm{kJ} / \mathrm{mol}$ ), considering that the reaction model can be determined from Ea for a single $\alpha=\alpha(T)$ curve that equals $\mathrm{Ea}$ obtained by means of isoconversional methods (Khawam and Flanagan 2005; Pratap et al. 2007). This suggests that the reaction of $\mathrm{Li}_{2} \mathrm{CO}_{3}$ with $\mathrm{ZrO}_{2}$ is governed by a diffusion-controlled mechanism, implying that the rate of formation of $\mathrm{m}-\mathrm{Li}_{2} \mathrm{ZrO}_{3}$ decreases proportionally with the thickness of its barrier layer (Khawam and Flanagan 2006).

The average particle size of the samples prepared at different temperatures was examined by DLS (see Fig. 9). As shown in Fig. 9, the average particle size of the sample obtained at $600{ }^{\circ} \mathrm{C}$ was $325 \mathrm{~nm}$ which, according to Fig. 1, is composed by $\mathrm{Li}_{2} \mathrm{CO}_{3}$ and $\mathrm{ZrO}_{2}$ particles. When the temperature was increased to $700{ }^{\circ} \mathrm{C}$, the average particle size increased slightly, probably due to the partial reaction of reactive $\mathrm{Li}_{2} \mathrm{CO}_{3}$ with $\mathrm{ZrO}_{2}$ (see Fig. 1), resulting in partial nucleation of lithium-containing zirconates $\left(\mathrm{Li}_{\mathrm{x}} \mathrm{Zr}_{\mathrm{y}} \mathrm{O}_{\mathrm{z}}\right)$ on the surface of $\mathrm{ZrO}_{2}$ particles. When the temperature

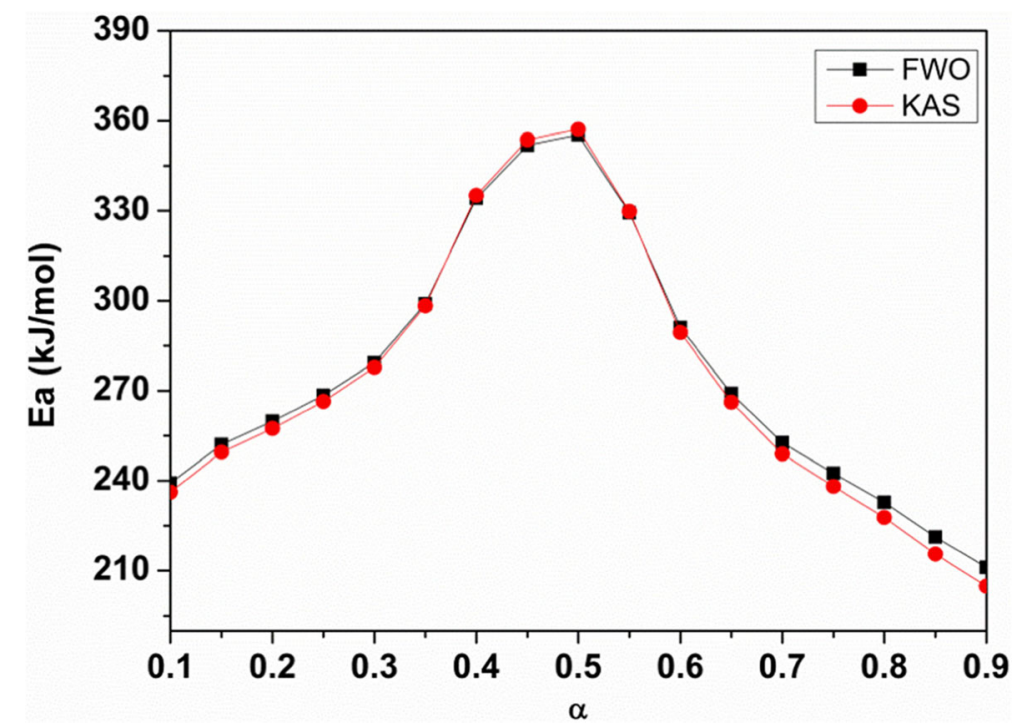

Fig. 7 Activation energy obtained from FWO and KAS methods as a function of a 
Table 2 Solid-state curve fitting parameter $\left(R^{2}\right)$ by CR method for TGA experiments at different heating rates

\begin{tabular}{|c|c|c|c|c|}
\hline \multirow[t]{2}{*}{ \# } & \multirow[t]{2}{*}{ Reaction model } & \multicolumn{3}{|l|}{$R^{2}$} \\
\hline & & $10^{\circ} \mathrm{C} / \mathrm{min}$ & $20^{\circ} \mathrm{C} / \mathrm{min}$ & $30^{\circ} \mathrm{C} / \mathrm{min}$ \\
\hline \multicolumn{5}{|c|}{ Nucleation models } \\
\hline 1 & Power law (P2) & 0.75187 & 0.795460 & 0.79543 \\
\hline 2 & Power law (P3) & 0.52183 & 0.64315 & 0.65993 \\
\hline 3 & Power law (P4) & 0.13 & 0.3616 & 0.41986 \\
\hline 4 & Avrami-Erofeyev (A2) & 0.85286 & 0.88944 & 0.91076 \\
\hline 5 & Avrami-Erofeyev (A3) & 0.77171 & 0.83513 & 0.86886 \\
\hline 6 & Avrami-Erofeyev (A4) & 0.61573 & 0.73777 & 0.79591 \\
\hline 7 & Modified Prout-Tompkins (B1) & 0.22116 & 0.2703 & 0.42012 \\
\hline \multicolumn{5}{|c|}{ Geometrical contraction models } \\
\hline 8 & Contracting area (R2) & 0.87958 & 0.89781 & 0.89985 \\
\hline 9 & Contracting volume (R3) & 0.88562 & 0.90587 & 0.91142 \\
\hline \multicolumn{5}{|c|}{ Diffusion models } \\
\hline 10 & One-dimensional diffusion (D1) & 0.89002 & 0.8995 & 0.89459 \\
\hline 11 & Two-dimensional diffusion (D2) & 0.89712 & 0.90829 & 0.90618 \\
\hline 12 & Three-dimensional diffusion (D3) & 0.90603 & 0.92164 & 0.93858 \\
\hline 13 & Ginstling-Brounshtein (D4) & 0.90018 & 0.91292 & 0.91269 \\
\hline \multicolumn{5}{|c|}{ Reaction-order models } \\
\hline 14 & Zero-order (F0/R1) & 0.85917 & 0.87468 & 0.87021 \\
\hline 15 & First-order (F1) & 0.89800 & 0.92163 & 0.9363 \\
\hline 16 & Second-order (F2) & 0.8773 & 0.91932 & 0.93746 \\
\hline 17 & Third-order (F3) & 0.75608 & 0.86045 & 0.89113 \\
\hline
\end{tabular}

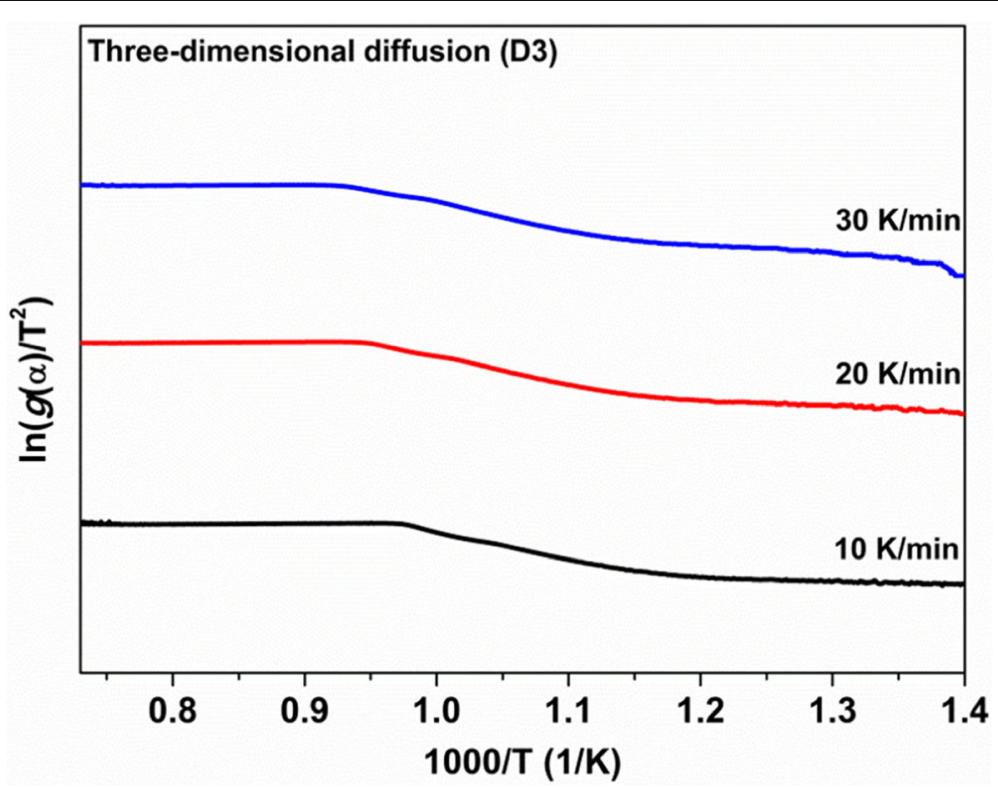

Fig. $8 \mathrm{CR}$ plot for the three-dimensional diffusion (D3) reaction model of the solid-state reaction heated at different heating rates 


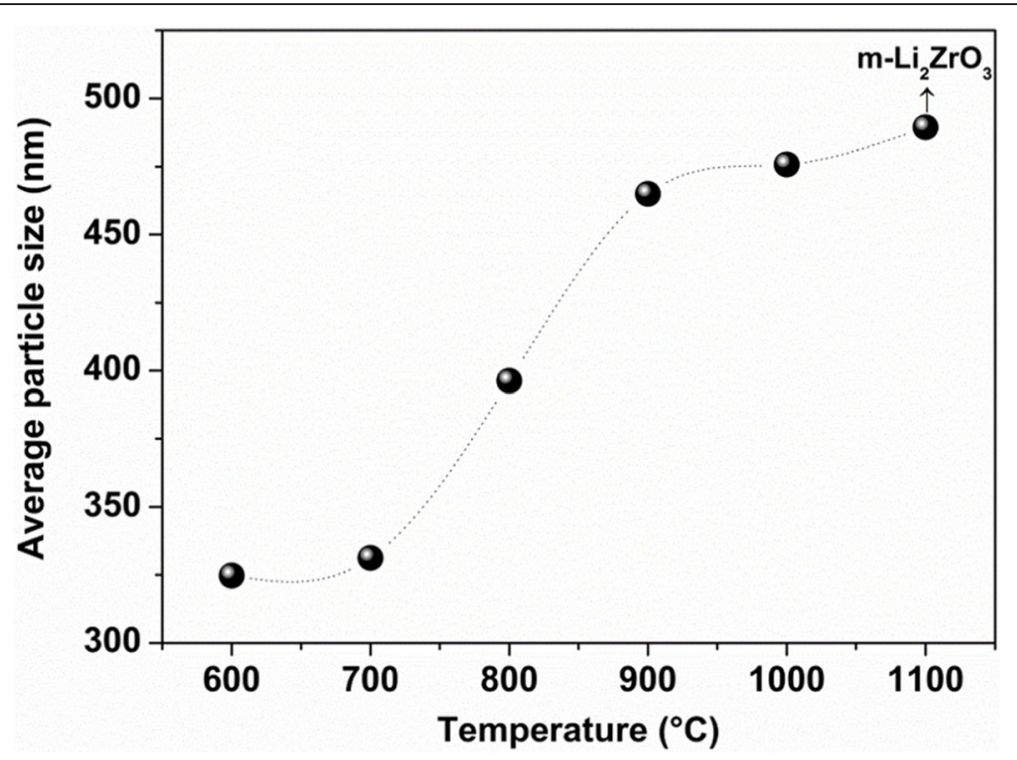

Fig. 9 Average particle size of samples prepared at different temperatures

was increased to $800{ }^{\circ} \mathrm{C}$, the average particle size increased to $396 \mathrm{~nm}$, suggesting both the nucleation and growth of $\mathrm{Li}_{\mathrm{x}} \mathrm{Zr}_{\mathrm{y}} \mathrm{O}_{\mathrm{z}}$ particles, because the reaction between the starting materials had been completed at this temperature (see Fig. 1). Further temperature increases resulted in increases in the average particle size due both to growth of $\mathrm{Li}_{\mathrm{x}} \mathrm{Zr}_{\mathrm{y}} \mathrm{O}_{\mathrm{z}}$ particles and formation of agglomerates, because of high temperatures. Thus, the average particle size of the sample obtained at $1100{ }^{\circ} \mathrm{C}$ was $490 \mathrm{~nm}$, which corresponds to pure $\mathrm{m}-\mathrm{Li}_{2} \mathrm{ZrO}_{3}$, according to XRD results.

Particle morphology of pure $\mathrm{m}-\mathrm{Li}_{2} \mathrm{ZrO}_{3}$ was also confirmed by TEM and HRTEM analysis. As shown in Fig. 10a, TEM image reveals that $\mathrm{m}-\mathrm{Li}_{2} \mathrm{ZrO}_{3}$ is composed of semispherical particles showing sizes of around $500 \mathrm{~nm}$. It is also possible to observe the formation of agglomerates, because of high temperature. These results are in accordance with the DLS results described above. Figure 10b shows the crystallographic structure of the as-synthesized $\mathrm{m}-\mathrm{Li}_{2} \mathrm{ZrO}_{3}$ at an atomic scale, with an interlayer spacing of $0.438 \mathrm{~nm}$. This result is matched with the interplanar distance of (110) plane for the standard $\mathrm{m}-\mathrm{Li}_{2} \mathrm{ZrO}_{3}$ (JCPDS 76-1150). When compared with other reports on the solidstate reaction (Sherstobitova et al. 2016; Pfeiffer and Knowles 2004; Yin et al. 2009; Hernández-Pérez et al. 2018), the present work succeeded in reducing from micron to submicron scale the average particle size of pure

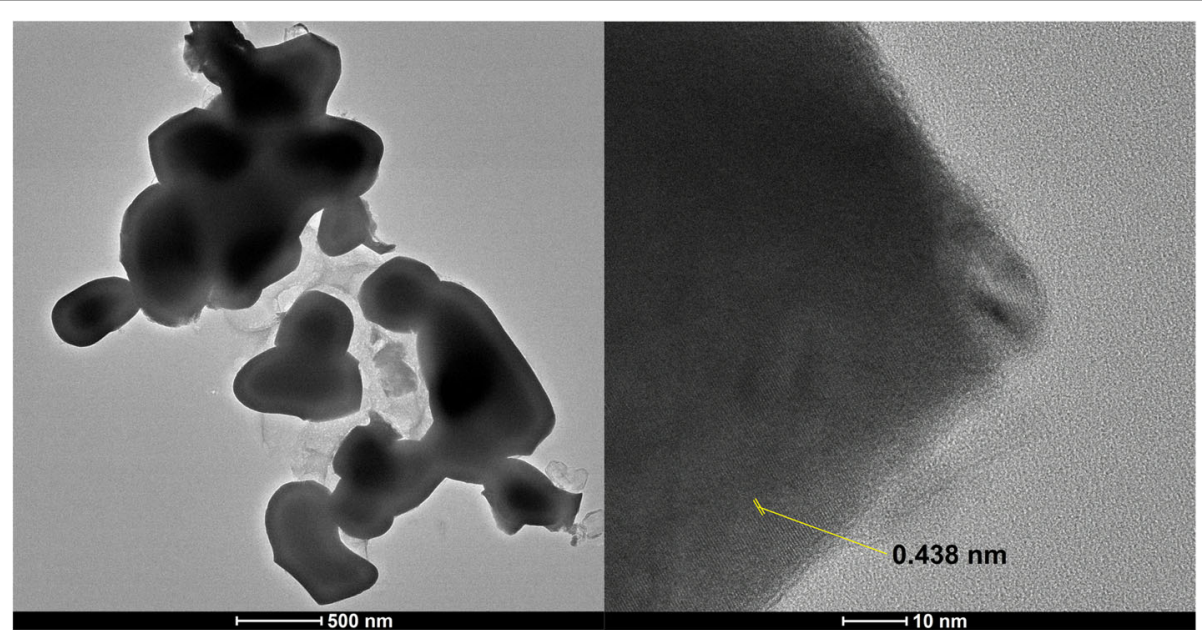

(a)

(b)

Fig. 10 a TEM and $\mathbf{b}$ HRTEM images of pure $\mathrm{m}-\mathrm{Li}_{2} \mathrm{ZrO}_{3}$ powders prepared by solid-state reaction 




Fig. 11 Schematic representation of the reaction model for the formation of $\mathrm{m}-\mathrm{Li}_{2} \mathrm{ZrO}_{3}$ during the solid-state reaction

$\mathrm{m}-\mathrm{Li}_{2} \mathrm{ZrO}_{3}$. This can be attributed to the very short reaction time of less than a minute used at high temperature.

Based on the results obtained in this work, along with the three-dimensional diffusion-controlled mechanism, a microscopic reaction model of the formation of $\mathrm{m}$ $\mathrm{Li}_{2} \mathrm{ZrO}_{3}$ is proposed. During the heating process, $\mathrm{Li}_{2} \mathrm{CO}_{3}$ melts and encloses the $\mathrm{ZrO}_{2}$ particles. Thus, the melted $\mathrm{Li}_{2} \mathrm{CO}_{3}$ reacts with $\mathrm{ZrO}_{2}$ to form a shell of tetragonal $\mathrm{Li}_{2} \mathrm{ZrO}_{3}$ and $\mathrm{Li}_{6} \mathrm{Zr}_{2} \mathrm{O}_{7}$ on the surface, accompanied by release of $\mathrm{CO}_{2}$, which diffuses out through the melted $\mathrm{Li}_{2} \mathrm{CO}_{3}$. This process continues with the decomposition of the melted $\mathrm{Li}_{2} \mathrm{CO}_{3}$ and $\mathrm{Li}^{+}$diffusion through the shell to the core of $\mathrm{ZrO}_{2}$ to thicken the product layer, in order to complete the formation of lithium-containing zirconates. This confirms that $\mathrm{CO}_{2}$ desorption plays an important role in this type of reaction [4]. With increasing reaction temperature, the phase transition of tetragonal to monoclinic $\mathrm{Li}_{2} \mathrm{ZrO}_{3}$, and the decomposition of $\mathrm{Li}_{6} \mathrm{Zr}_{2} \mathrm{O}_{7}$ to release $\mathrm{Li}_{2} \mathrm{O}$ are favored, resulting in the formation of pure $\mathrm{m}-\mathrm{Li}_{2} \mathrm{ZrO}_{3}$ in the sample. A schematic representation of the proposed microscopic reaction model is shown in Fig. 11.

\section{Conclusions}

Non-isothermal reaction mechanism and kinetic parameters have been determined for the first time for the synthesis of monoclinic lithium zirconate $\left(\mathrm{m}-\mathrm{Li}_{2} \mathrm{ZrO}_{3}\right)$ via solid-state reaction of $\mathrm{Li}_{2} \mathrm{CO}_{3}$ with $\mathrm{ZrO}_{2}$. Kinetic analysis was investigated by processing of TG-DTA, along with XRD, DLS, and HRTEM. Pure $\mathrm{m}-\mathrm{Li}_{2} \mathrm{ZrO}_{3}$ powders of about $490 \mathrm{~nm}$ and semispherical morphology were obtained at $1100{ }^{\circ} \mathrm{C}$. This method succeeded in reducing from micron to submicron scale the average particle size of pure $\mathrm{m}-\mathrm{Li}_{2} \mathrm{ZrO}_{3}$ synthesized by using conventional solid-state reaction, because of the very short reaction time of less than a minute used at high temperature. Kinetics parameters were calculated and compared through two different isoconversional methods: FWO and KAS. The average value of activation energy obtained from the FWO method $(274.73 \mathrm{~kJ} / \mathrm{mol})$ was very near to those obtained from KAS $(272.50 \mathrm{~kJ} / \mathrm{mol})$, which demonstrates a good agreement in the calculation of the kinetic parameters. On the other hand, the reaction mechanism was determined by model-fitting method using $\mathrm{CR}$ approximation. It was found that the reaction between $\mathrm{Li}_{2} \mathrm{CO}_{3}$ and $\mathrm{ZrO}_{2}$ follows the diffusion mechanism, being the three-dimensional diffusioncontrolled reaction the best fitted model for the formation of $\mathrm{m}-\mathrm{Li}_{2} \mathrm{ZrO}_{3}$. This analysis is very important in order to optimize the solid-state process for large-scale production, and advanced applications of $\mathrm{m}-\mathrm{Li}_{2} \mathrm{ZrO}_{3}$.

\section{Abbreviations}

A: Pre-exponential factor; CR: Coats-Redfern approximation; DLS: Dynamic light scattering; Ea: Activation energy; FWO: Flynn-Wall-Ozawa method; HRTE M: High-resolution transmission electron microscopy; KAS: Kissinger-AkahiraSunose method; $\mathrm{m}-\mathrm{Li}_{2} \mathrm{ZrO}_{3}$ : Monoclinic lithium zirconate; TG-

DTA: Thermogravimetric and differential-thermal analysis; XRD: X-ray diffraction

\section{Acknowledgements}

The authors acknowledge Lic. María Alejandra Floridia and Dr. Alberto Caneiro (Y-TEC) for HRTEM measurements.

\section{Authors' contributions}

All authors read and approved the final version of the manuscript for publication.

\section{Funding}

This work was supported by CONICET (National Scientific and Technical Research Council) and ANPCyT (National Agency for Scientific and Technological Promotion; PICT 2016-1193).

\section{Availability of data and materials}

All raw data used in this manuscript are available and could be supplied upon request. 


\section{Declarations}

\section{Competing interests}

The authors declare that they have no competing interests.

\section{Author details}

'CETMIC Technological Center of Mineral Resources and Ceramics (UNLP-CIC-CONICET), Cno. Centenario y 506, M.B. Gonnet, 1897 Buenos Aires, Argentina. ${ }^{2}$ Department of Chemistry, Faculty of Exact Sciences, National University of La Plata (UNLP), 47 y 115, La Plata, 1900 Buenos Aires, Argentina. ${ }^{3}$ INIFTA Research Institute of Theoretical and Applied Physical Chemistry (UNLP-CONICET), CC. 16, Suc. 4, La Plata, 1900 Buenos Aires, Argentina.

Received: 24 June 2020 Accepted: 4 March 2021

Published online: 26 March 2021

\section{References}

Chattaraj D. Structural, electronic, elastic and thermodynamic properties of Li2ZrO3: a comprehensive study using DFT formalism. J Nucl Mater. 2017:496: 286-92. https://doi.org/10.1016/j.jnucmat.2017.09.040.

Chitnis A, Chakraborty B, Tripathi BM, Tyagi AK, Garg N. High pressure stability of lithium metatitanate and metazirconate: insight from experiments \& ab-initio calculations. J Nucl Mater. 2018;499:334-43. https://doi.org/10.1016/j.jnucma t.2017.11.048.

Dhyani V, Kumar J, Bhaskar T. Thermal decomposition kinetics of sorghum straw via thermogravimetric analysis. Bioresour Technol. 2017;245(Pt A):1122-9. https://doi.org/10.1016/j.biortech.2017.08.189.

Dong Y, Zhao Y, Duan H, Huang J. Electrochemical performance and lithium-ion insertion/extraction mechanism studies of the novel Li2ZrO3 anode materials. Electrochim Acta. 2015;161:219-25. https://doi.org/10.1016/j.electa cta.2015.01.220.

Ebrahimi-Kahrizsangi R, Abbasi MH. Evaluation of reliability of coatsRedfern method for kinetic analysis of non-isothermal TGA. Trans Nonferrous Met Soc China. 2008;18(1):217-21. https://doi.org/10.1016/ S1003-6326(08)60039-4.

Ghuge NS, Mandal D. Synthesis of LiDyO2 by solid-state reaction process and study of reaction kinetics by using TG-DTA and XRD techniques. Indian Chem Eng. 2017;59(2):101-16. https://doi.org/10.1080/00194506.201 6.1139469 .

Hernández-Pérez TC, Bernal R, Cruz-Vázquez C, Brown F, Mendoza-Córdova A, Salas-Juárez CJ, et al. Afterglow dosimetry performance of beta particle irradiated lithium zirconate. Appl Radiat Isot Data Instrum Methods Use Agric Ind Med. 2018;138:2-5. https://doi.org/10.1016/j.apra diso.2017.10.027

Ida J, Lin YS. Mechanism of high-temperature CO2 sorption on lithium Zirconate. Environ Sci Technol. 2003;37(9):1999-2004. https://doi.org/10.1 021/es0259032

Jiang G, Wei L. Analysis of pyrolysis kinetic model for processing of thermogravimetric analysis data. In: Mhadhbi M, editor. Phase change materials and their applications; 2018. InTech.

Khawam A, Flanagan DR. Complementary use of model-free and modelistic methods in the analysis of solid-state kinetics. J Phys Chem B. 2005;109(20): 10073-80. https://doi.org/10.1021/jp050589u.

Khawam A, Flanagan DR. Solid-state kinetic models: basics and mathematical fundamentals. J Phys Chem B. 2006;110(35):17315-28. https://doi.org/10.1 021/jp062746a.

Kongkaew N, Pruksakit W, Patumsawad S. Thermogravimetric kinetic analysis of the pyrolysis of rice straw. Energy Procedia. 2015;79:663-70. https://doi.org/1 0.1016/j.egypro.2015.11.552.

Kordatos A, Christopoulos S-RG, Kelaidis N, Chroneos A. Defect processes in Li2ZrO3: insights from atomistic modelling. J Mater Sci Mater Electron. 2017; 28(16):11789-93. https://doi.org/10.1007/s10854-017-6984-5.

Lee G-Y, Song J, Lee J-S. Reaction kinetics and phase transformation during hydrogen reduction of spherical Fe 203 nanopowder agglomerates. Powder Technol. 2016;302:215-21. https://doi.org/10.1016/j.powtec.2016. 07.038

Leng Y. Materials characterization: introduction to microscopic and spectroscopic methods. Second ed. Weinheim: Wiley-VCH; 2013. https://doi.org/10.1002/ 9783527670772.
Li T, Song F, Zhang J, Liu S, Xing B, Bai Y. Pyrolysis characteristics of soil humic substances using TG-FTIR-MS combined with kinetic models. Sci Total Environ. 2020;698:134237. https://doi.org/10.1016/j.scitotenv.2019.134237.

Liu Y, Lv X, You Z, Lv X. Kinetics study on non-isothermal carbothermic reduction of nickel laterite ore in presence of Na2SO4. Powder Technol. 2020;362:48692. https://doi.org/10.1016/j.powtec.2019.11.103.

Lu C-H, Wei-Cheng L. Reaction mechanism and kinetics analysis of lithium nickel oxide during solid-state reaction. J Mater Chem. 2000;10(6):1403-7. https:// doi.org/10.1039/a909130k

Lu C-H, Wu P-C. Reaction mechanism and kinetic analysis of the formation of Sr2SiO4 via solid-state reaction. J Alloys Compd. 2008;466(1-2):457-62. https://doi.org/10.1016/j.jallcom.2007.11.066.

Lv X, Lv W, You Z, Lv X, Bai C. Non-isothermal kinetics study on carbothermic reduction of nickel laterite ore. Powder Technol. 2018;340:495-501. https:// doi.org/10.1016/j.powtec.2018.09.061.

Mandal D. Reaction kinetics for the synthesis of lithium-titanate (Li2TiO3) by solid state reaction. J Sci Technol. 2014:4:8.

Marinović-Cincović M, Janković B, Milićević B, Antić Ž, Whiffen RK, Dramićanin MD. The comparative kinetic analysis of the non-isothermal crystallization process of Eu3+ doped $\mathrm{Zn} 2 \mathrm{SiO} 4$ powders prepared via polymer induced sol-gel method. Powder Technol. 2013;249:497-512. https://doi.org/10.1016/j. powtec.2013.09.020.

Milićević B, Marinović-Cincović M, Dramićanin MD. Non-isothermal crystallization kinetics of Y2Ti2O7. Powder Technol. 2017;310:67-73. https://doi.org/10.1016/ j.powtec.2017.01.001.

Oyaidzu M, Kimura H, Yoshikawa A, Nishikawa Y, Munakata K, Okada M, et al. Correlation between annihilation of irradiation defects and tritium release in neutron-irradiated lithium zirconate. Fusion Eng Des. 2006;81(1-7):583-8. https://doi.org/10.1016/j.fusengdes.2005.06.361.

Pfeiffer $\mathrm{H}$, Knowles KM. Reaction mechanisms and kinetics of the synthesis and decomposition of lithium metazirconate through solid-state reaction. J Eur Ceram Soc. 2004:24(8):2433-43. https://doi.org/10.1016/S0955-221 9(03)00630-7.

Pratap A, Lilly Shanker Rao T, Lad KN, Dhurandhar HD. Isoconversional vs. model fitting methods: a case study of crystallization kinetics of a Fe-based metallic glass. J Therm Anal Calorim. 2007;89(2):399-405. https://doi.org/10.1007/s1 0973-006-8160-7.

Sherstobitova EA, Gubkin AF, Bobrikov IA, Kalashnova AV, Pantyukhina MI. Bottlenecked ionic transport in Li2ZrO3: high temperature neutron diffraction and impedance spectroscopy. Electrochim Acta. 2016;209:574-81. https://doi. org/10.1016/j.electacta.2016.05.113

Sree Rama Murthy A, Gnanasekaran T, Jayaraman V. Preparation and characterization of some lithium - ion conductors. Solid State Ionics. 2017; 303:138-43. https://doi.org/10.1016/j.ssi.2017.03.006.

Taddia M, Modesti P, Albertazzi A. Determination of macro-constituents in lithium zirconate for tritium-breeding applications. J Nucl Mater. 2005;336(2-3):173-6. https://doi.org/10.1016/j.jnucmat.2004.09.011.

Trawiński B, Bochentyn B, Łapiński M, Kusz B. A study of the kinetics of bismuth telluride synthesis by an oxide reduction method. Thermochim Acta. 2020; 683:178437. https://doi.org/10.1016/j.tca.2019.178437.

Vyazovkin S, Burnham AK, Criado JM, Pérez-Maqueda LA, Popescu C, Sbirrazzuoli N. ICTAC kinetics committee recommendations for performing kinetic computations on thermal analysis data. Thermochim Acta. 2011;520(1-2):119. https://doi.org/10.1016/j.tca.2011.03.034.

Vyazovkin S, Burnham AK, Favergeon L, Koga N, Moukhina E, Pérez-Maqueda LA, et al. ICTAC kinetics committee recommendations for analysis of multi-step kinetics. Thermochim Acta. 2020;689:178597. https://doi.org/1 $0.1016 /$ j.tca.2020.178597

Vyazovkin S, Chrissafis K, Di Lorenzo ML, et al. ICTAC kinetics committee recommendations for collecting experimental thermal analysis data for kinetic computations. Thermochim Acta. 2014;590:1-23. https://doi.org/10.1 016/j.tca.2014.05.036

Wang C, Dou B, Song Y, Chen H, Xu Y, Xie B. High temperature CO2 sorption on Li2ZrO3 based sorbents. Ind Eng Chem Res. 2014;53(32):12744-52. https:// doi.org/10.1021/ie502042p.

Wang S, An C, Zhang Q-H. Syntheses and structures of lithium zirconates for high-temperature CO2 absorption. J Mater Chem A. 2013;1(11):3540-50. https://doi.org/10.1039/C2TA00700B.

Woo S-K, Lee S-W, Yu J-H. Carbon dioxide sorption properties and sintering behavior of lithium zirconate prepared by solid-state reaction. J Korean Ceram Soc. 2006;43(5):309-14. https://doi.org/10.4191/KCERS.2006.43.5.309. 
Wyers GP, Cordfunke EHP. Phase relations in the system Li2O-ZrO2. J Nucl Mater. 1989;168(1-2):24-30. https://doi.org/10.1016/0022-3115(89)90560-6.

Yin X-S, He X-L, Peng J, et al. Synthesis and characterization of LixZryOz compounds. Chinese J Inorg Chem. 2009;25:1221-6.

Zhan X, Cheng Y-T, Shirpour M. Nonstoichiometry and Li-ion transport in lithium zirconate: the role of oxygen vacancies. J Am Ceram Soc. 2018;101(9):405365. https://doi.org/10.1111/jace.15583.

\section{Publisher's Note}

Springer Nature remains neutral with regard to jurisdictional claims in published maps and institutional affiliations.

Submit your manuscript to a SpringerOpen ${ }^{\circ}$ journal and benefit from:

- Convenient online submission

- Rigorous peer review

- Open access: articles freely available online

- High visibility within the field

- Retaining the copyright to your article

Submit your next manuscript at $\boldsymbol{\sim}$ springeropen.com 